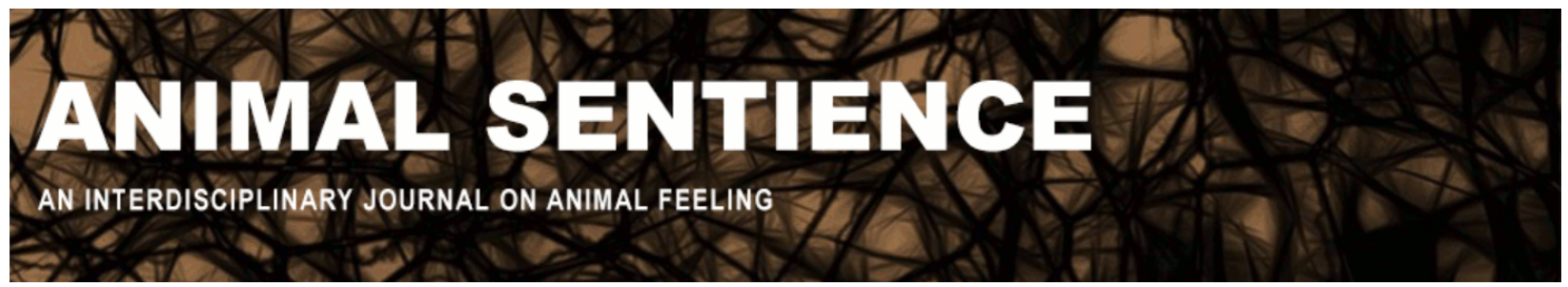

Woodruff, Michael L. (2017) Scientific uncertainty and the animal sentience precautionary principle. Animal Sentience 16(11)

DOI: $10.51291 / 2377-7478.1237$

Date of submission: 2017-10-29

Date of acceptance: 2017-11-03

(c)

This article has appeared in the journal Animal

Sentience, a peer-reviewed journal on animal

cognition and feeling. It has been made open access,

free for all, by WellBeing International and deposited

in the WBI Studies Repository. For more information,

please contact

wbisr-info@wellbeingintl.org.

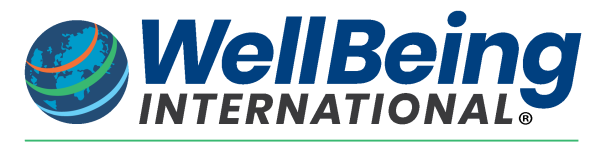

SOLUTIONS FOR PEOPLE, ANIMALS AND ENVIRONMENT 


\title{
Scientific uncertainty and the animal sentience precautionary principle
}

Commentary on Birch on Precautionary Principle

\author{
Michael L. Woodruff \\ Departments of Biomedical Sciences and Psychology \\ East Tennessee State University
}

\begin{abstract}
Jonathan Birch offers the animal sentience precautionary principle (ASPP) as a framework for assigning sentience to animals. In doing this, he defines a BAR which when crossed will lead to action (ACT) and implementation of the ASPP. His effort to create a clear empirical basis for implementation of the precautionary principle in the area of animal welfare regulation is important. I argue, however, that his BAR is so low that the evidence supporting ACT is in danger of being overwhelmed by the problems of induction and the underdetermination of theory by evidence. If this happens, policy makers might well disregard the ASPP and fail to include sentient species in animal welfare regulation. I suggest that the BAR needs to be raised by inclusion of more independent indicators of sentience than those required by Birch.
\end{abstract}

\footnotetext{
Michael L. Woodruff is Professor Emeritus of Biomedical Sciences and of Psychology at East Tennessee State University. Author of more than 120 professional publications, his research interests include cognitive neuroscience and the philosophy of mind. https://www.researchgate.net/profile/Michael_Woodruff3/info
}

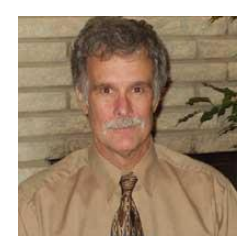

Birch (2017) proposes the Animal Sentience Precautionary Principle (ASPP) as a way of resolving a conflict that clouds efforts to extend animal welfare policies to certain marine invertebrates. On my view, this conflict arises because, on the one hand, the best public policy will presumably be shaped by scientific evidence, but, on the other hand, there is always uncertainty inherent in the interpretation of scientific data (Douglas 2009). Birch's concern is with the criteria for determining scientifically whether a particular species is sentient. As Birch notes, scientific determination of sentience is especially difficult in part due to the "other minds" problem. Yet decisions about what species should be protected by animal welfare legislation must still be made. Birch proposes the ASPP as a guide to making this decision and recommends a low BAR for its implementation.

I am concerned that a low BAR will produce enough uncertainty about the level of scientific support for the ASPP that policy makers, particularly legislators, will find it easy to ignore evidence supporting it in favor of contradictory evidence presented by groups opposing additional regulations. A historic example of the ability of opponents of regulation to successfully use scientific uncertainty to block implementation of the precautionary principle can be found in the six-decade long fight to ban tetraethyl lead from gasoline in the United States (Nriagu 1990; Nriagu 1994).

Scientific uncertainty comes from two problems inherent in the scientific method: the problem of induction (POI) and the problem of the underdetermination of theory by evidence (Douglas 2009; Haack 2007; Harper 2015). The POI arises because it is not logically necessary that a phenomenon observed under one set of conditions will recur under different conditions 
intended to reproduce that phenomenon. The POI occurs twice in the implementation of the ASPP.

First, an indicator of sentience observed in one experiment may not predict that it will be found in a slightly different experiment. For example, Magee and Elwood (2013) observed that European shore crabs spent less time under a shelter in which they had experienced electrical shock than in one in which they had not. They interpreted this to mean that shore crabs experience pain, i.e., are sentient. However, using a slightly different experimental design, the same researchers failed to find that shore crabs learn to avoid shelter in which they experienced shock (Magee and Elwood, 2016).

Second, Birch's BAR requires the ability to predict sentience in an entire order from the presence of an indicator of sentience in one of its species. Opiate-induced analgesia, a presumed indicator of sentience, has been shown in two species of crab (Chasmagnathus granulatus, Lozada et al. 1988, and Carcinus mediterraneus, Bergamo et al. 1992). However, Barr and Elwood (2011) failed to find evidence of morphine analgesia in the shore crab (Carcinus maenas). Thus, the ability to generalize sentience inductively from two species of crab to sentience in all species in the order decapoda appears to be suspect, at least when morphine-induced analgesia is used as an indicator.

In the discussion above, I accepted that the presence of discriminative avoidance learning and morphine-induced analgesia provide valid indicators of sentience in crabs. However, for fishes this same interpretation of similar results has been vehemently denied (e.g., Key 2016; Rose et al. 2012). This disagreement concerning the meaning of the presence of avoidance learning and analgesia in fish points to the problem of underdetermination of theory by evidence, specifically to the problem of contrastive underdetermination (CUD). CUD refers to the problem that data obtained in any given experiment can always be interpreted to support more than one hypothesis (Stanford 2016). In the examples given above, associative learning not requiring sentience can reasonably be proposed to account for the ability of crabs to acquire the observed avoidance behavior, and the analgesic effects of morphine may have been produced by the blockade of nonsentient nociception (Key 2016; Rose et al. 2012).

Birch has offered a very useful pragmatic framework for applying the precautionary principle to the assignment of sentience to animals. He has also challenged the scientific community to refine the parameters of his BAR. I argue that to be effective in influencing policy makers, the BAR needs to be set quite a bit higher than Birch proposes. In another commentary on this target article, Brown (2017) also recommends a higher bar for establishing sentience. His bar would include establishing indicators of sentience in more than one species. He then outlines an evolutionary phylogenetic approach for legitimately generalizing to many species from a few species in which accepted indicators of sentience have been found.

In addition, the number of indicators of sentience needs to be substantially increased. In keeping with the risk assessment model adumbrated by Brown, I suggest that an approach patterned after the method developed for detecting minimal neurobehavioral toxicity (Moser 2011) should be developed. This means a more laborious testing regime than desired by Birch, but it will reduce the POI and the CUD by applying data from several independent disciplines to defining sentience in animals. Minimizing POI and CUD by accumulating multidisciplinary scientific evidence has proved effective in bringing the precautionary principle to bear on environmental 
health policy (Nriagu 1998). I suggest that it will also be useful in encouraging implementation of the ASPP.

\section{References}

Barr, S. and Elwood, R. W. (2011). No evidence of morphine analgesia to noxious shock in the shore crab, Carcinus maenas. Behavioral Processes 86:340-344

Bergamo, P., Maldonado, H. and Miralto, A. (1992). Opiate effect on the threat display in the crab Carcinus mediterraneus. Pharmacology Biochemistry and Behavior 42:323-326

Birch, J. (2017). Animal sentience and the precautionary principle. Animal Sentience 16(1)

Brown, C. (2017). A risk assessment and phylogenetic approach. Animal Sentience, 16(3)

Douglas, H, (2009). Science, Policy, and the Value-Free Ideal. Pittsburgh: University of Pittsburgh Press

Haack, S. (2007). Science within reason: Between scientism and cynicism. Amherst, NY: Prometheus Books

Harker, D. (2015). Creating Scientific Controversies: Uncertainty and Bias in Science and Society Cambridge, UK: Cambridge University Press

Key, B. (2016). Why fish do not feel pain. Animal Sentience 3(1)

Lozada, M., Romano, A. and Maldonado, H. (1988). Effect of morphine and naloxone on a defensive response of the crab Chasmagnathus granulatus. Pharmacology Biochemistry and Behavior 30:635-640

Magee, B. and Elwood, R. W. (2016). No discrimination shock avoidance with sequential presentation of stimuli but shore crabs still reduce shock exposure. The Company of Biologists Ltd / Biology Open (2016) 5: 883-888 doi:10.1242/bio.019216

Moser, V. C. (2011). Functional assays for neurotoxicity testing. Toxicologic Pathology 39: 3-45.

Nriagu, J. O. (1990). "The rise and fall of leaded gasoline." Science of The Total Environment, 92: $13-28$

Nriagu, J. O. (1998). Clair Patterson and Robert Kehoe's paradigm of "show me the data" on environmental lead poisoning. Environmental Research, 78: 71-78

Rose, J. D., Arlinghaus, R., Cooke, S. J., Diggles, B. K., Sawynok, Stevens, E. D. and Wynne, C. D. L. (2012). Can fish really feel pain? Fish and Fisheries, 15, 97-133

Stanford, P. K. (2016). "Underdetermination of Scientific Theory", The Stanford Encyclopedia of Philosophy (Spring Edition), E. N. Zalta (ed.) 


\section{ANIMAL CONSCIOUSNESS}

On November 17-18, 2017, the NYU Center for Mind, Brain and Consciousness, the NYU Center for Bioethics, and NYU Animal Studies will host a conference on Animal Consciousness.

This conference will bring together philosophers and scientists to discuss questions such as: Are invertebrates conscious? Do fish feel pain? Are nonhuman mammals self-conscious? How did consciousness evolve? How does research on animal consciousness affect the ethical treatment of animals? What is the impact of issues about animal consciousness on theories of consciousness and vice versa? What are the best methods for assessing consciousness in nonhuman animals?

\section{Speakers and panelists include:}

Colin Allen (University of Pittsburgh, Department of History \& Philosophy of Science), Andrew Barron (Macquarie, Cognitive Neuroethology),

Victoria Braithwaite (Penn State, Biology), Peter Carruthers (Maryland,

Philosophy), Marian Dawkins (Oxford, Zoology), Dan Dennett (Tufts,

Philosophy), David Edelman (San Diego, Neuroscience),

Todd Feinberg (Mt. Sinai, Neurology), Peter Godfey-Smith (Sydney,

Philosophy), Lori Gruen (Wesleyan, Philosophy), Brian Hare (Duke, Evolutionary

Anthropology), Stevan Harnad (Montreal, Cognitive Science), Eva Jablonka (Tel

Aviv, Cohn Institute), Björn Merker (Neuroscience), Diana Reiss (Hunter,

Psychology), Peter Singer (Princeton, Philosophy), Michael Tye (Texas, Philosophy)

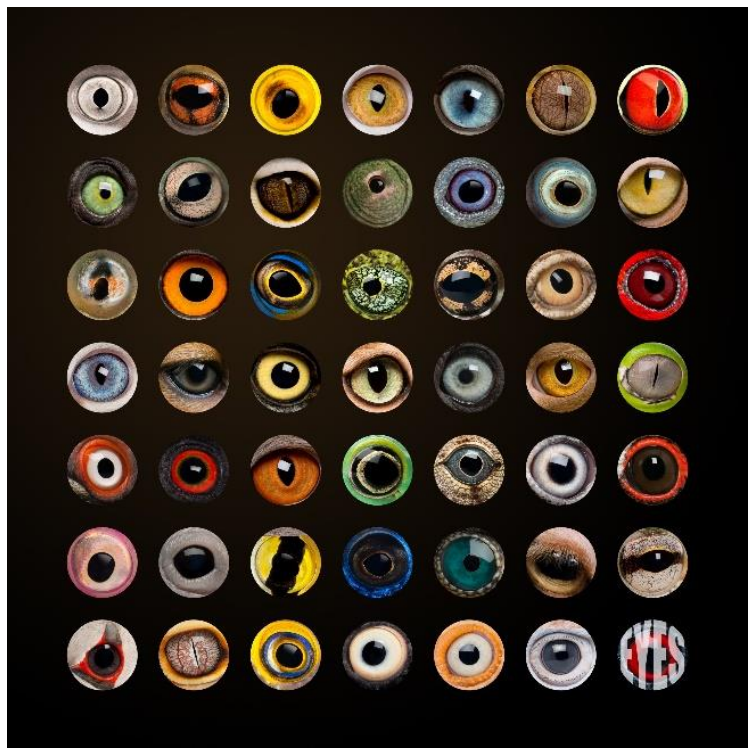

Organizers: Ned Block, David Chalmers, Dale Jamieson, S. Matthew Liao.

The conference will run from 9am on Friday November 17 to $6 \mathrm{pm}$ on Saturday November 18 at the NYU Cantor Film Center (36 E 8th St).

Friday sessions will include "Invertebrates and the evolution of consciousness", "Do fish feel pain?", and "Animal consciousness and ethics".

Saturday sessions will include "Animal self-consciousness", "Animal consciousness and theories of consciousness", and a panel discussion.

A detailed schedule will be circulated closer to the conference date.

Registration is free but required.

\section{Register here.}

\section{See also the conference website}

